Natural Hazards and Earth System Sciences (2002) 2: 121-128

(C) European Geosciences Union 2002

\title{
Snow drift: acoustic sensors for avalanche warning and research
}

\author{
M. Lehning ${ }^{1}$, F. Naaim ${ }^{2}$, M. Naaim ${ }^{2}$, B. Brabec ${ }^{1}$, J. Doorschot ${ }^{1}$, Y. Durand ${ }^{3}$, G. Guyomarc'h ${ }^{3}$, J.-L. Michaux ${ }^{2}$, and \\ M. Zimmerli ${ }^{1}$ \\ ${ }^{1}$ Swiss Federal Institute for Snow and Avalanche Research SLF, Flüelastr. 11, CH-7260 Davos, Switzerland \\ ${ }^{2}$ CEMAGREF-ETNA, BP.76 Domaine Universitaire, F-38402 Saint Martin d'Hères, France \\ ${ }^{3}$ METEO-FRANCE, Centre d'Etudes de la Neige, 1441 rue de la piscine, F-38406 Saint Martin d'Hères Cedex, France
}

Received: 20 September 2001 - Revised: 16 January 2002 - Accepted: 18 January 2002

\begin{abstract}
Based on wind tunnel measurements at the CSTB (Jules Verne) facility in Nantes and based on field observations at the SLF experimental site Versuchsfeld Weissfluhjoch, two acoustic wind drift sensors are evaluated against different mechanical snow traps and one optical snow particle counter. The focus of the work is the suitability of the acoustic sensors for applications such as avalanche warning and research. Although the acoustic sensors have not yet reached the accuracy required for typical research applications, they can, however, be useful for snow drift monitoring to help avalanche forecasters. The main problem of the acoustic sensors is a difficult calibration that has to take into account the variable snow properties. Further difficulties arise from snow fall and high wind speeds. However, the sensor is robust and can be operated remotely under harsh conditions. It is emphasized that due to the lack of an accurate reference method for snow drift measurements, all sensors play a role in improving and evaluating snow drift models. Finally, current operational snow drift models and snow drift sensors are compared with respect to their usefulness as an aid for avalanche warning. While drift sensors always make a point measurement, the models are able to give a more representative drift index that is valid for a larger area. Therefore, models have the potential to replace difficult observations such as snow drift in operational applications.
\end{abstract}

\section{Introduction}

Redistribution of snow by wind is a major feature of flat terrain, but particularly also of mountainous areas. It influences avalanche danger, it blocks roads and causes severe problems around buildings. In addition, the seasonal ablation or accumulation of snow at specific locations is very important to the growth of vegetation, such as avalanche protection forests. Despite its significance, blowing and drifting snow is difficult to assess quantitatively because of its complex nature.

Correspondence to: M. Lehning (lehning@ slf.ch)
Current models on snow drift are either only applicable in flat terrain, are still too complex for an operational application (Lehning et al., 2000b), or offer only limited information on snow drift, such as the SNOWPACK drift index (Lehning et al., 2000a). On the other hand, snow drift is also difficult to measure. While mechanical traps (Mellor 1960; Budd et al., 1966) are probably still the best reference, they require more or less continuous manual operation and are thus not suitable for remote locations or long-term monitoring. Optical sensors (Schmidt, 1977; Brown and Pomeroy, 1989; Sato and Kimura, 1993) have been very successful for research applications, but suffer from the fact that they give a single flux value at one specific height. In addition, they have not been used, to our knowledge, for long-term monitoring applications or at remote sites. New developments of acoustic sensors have taken place recently (Chritin et al., 1999; Font et al., 1998). Jaedicke (2001) gives examples of possible applications of acoustic snow drift sensors. He emphasizes the advantages of acoustic sensors for snow drift monitoring at remote locations, but could not present any evaluation of the accuracy of the measurements. We present a complete evaluation of the new acoustic sensors for snow drift and discuss their applications for research or avalanche warning. We compare the suitability of sensors for operational applications with the suitability of numerical models.

\section{Sensors}

The focus of the sensor tests is on the acoustic sensors. Two sensors were tested: the Swiss sensor FlowCapt ${ }^{\mathrm{TM}}$ (Chritin et al., 1999), built by IAV Engineering, and the French acoustic sensor (Font et al., 1998), developed by CEMAGREFS's ETNA unit in collaboration with Hydroemac. Both are based on the same principle: They consist of a tube with a microphone in it. When a snow particle hits the tube the microphone detects the impact sound, which is supposed to depend on the impact momentum and, therefore, the sensor can be calibrated to give a mass flux rate, assuming that the snow 

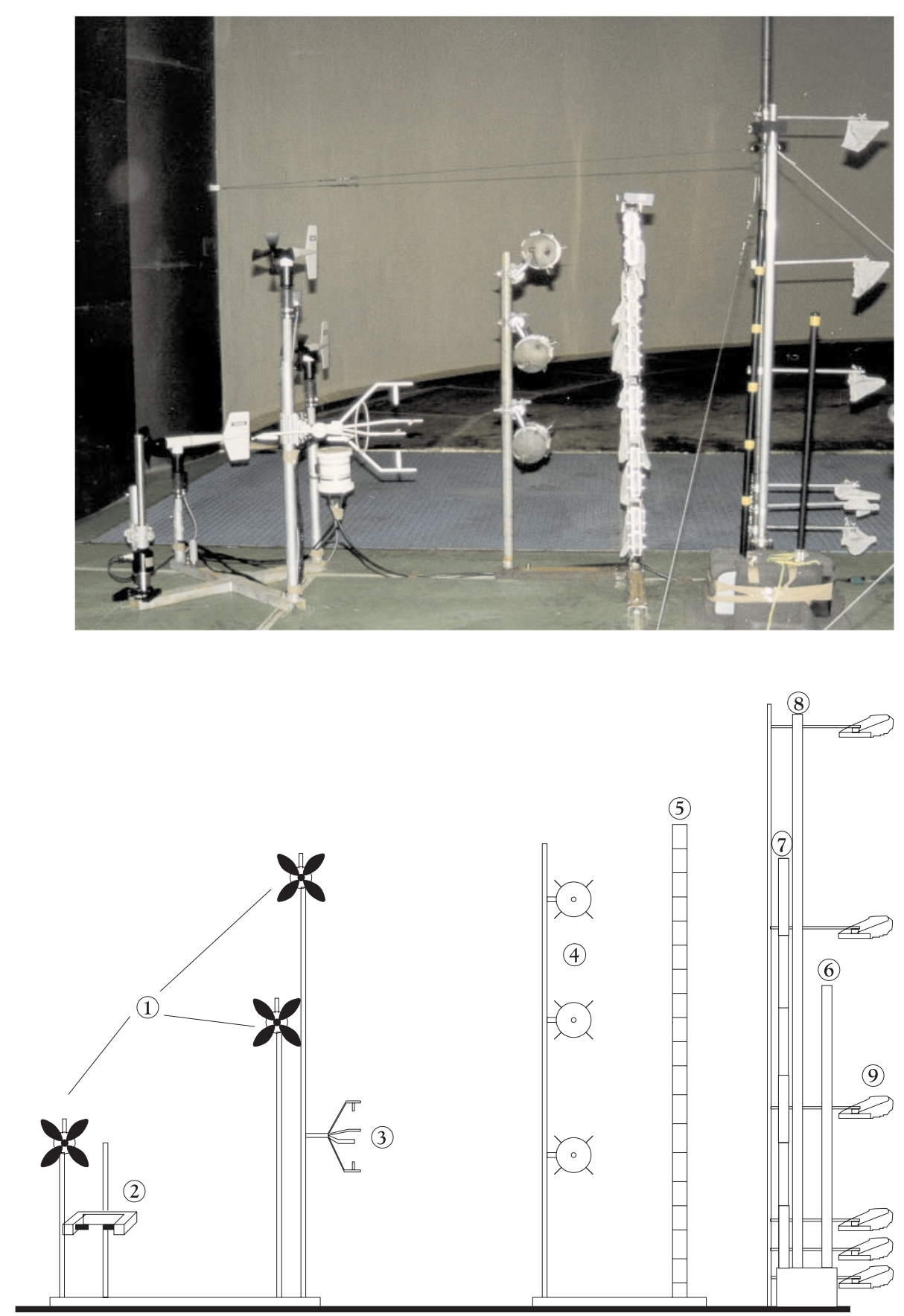

Fig. 1. Photograph of the end of the wind tunnel test section with sensors and a schematic diagram showing the location of the sensors.

grains always have the same elastic properties. The sensors have different design and development status.

FlowCapt is offered with a complete calibration, providing the mass flux of snow in $\mathrm{kg} \mathrm{m}^{-2} \mathrm{~s}^{-1}$. It also outputs an estimation of wind velocity, based on an analysis of the noise created by turbulence. To distinguish between noise from snow particles and air turbulence, the signal processing algorithm uses spectral analysis. Wind creates a signal with a lower frequency than the impact of particles on the tube. The tube is coated with Teflon to prevent riming. The sen- sor is available as a single tube instrument (FlowCapt100), which gives an integrated mass flux over the length of the tube. For research purposes, multi-segment sensors, with up to six independent tubes, are made (FlowCapt620 and FlowCapt520). The tests of the wind measuring functionality of FlowCapt have shown that the present sensors are not able to measure wind speed. Therefore, this functionality will not be discussed further in the current paper.

The French sensor is at present only available as a single segment instrument with a $2 \mathrm{~m}$ aluminium tube and one mi- 
(a)

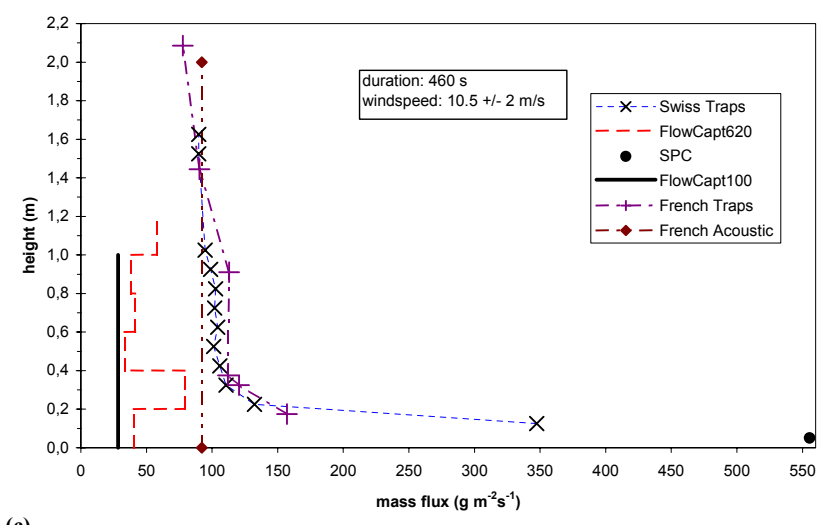

(c)

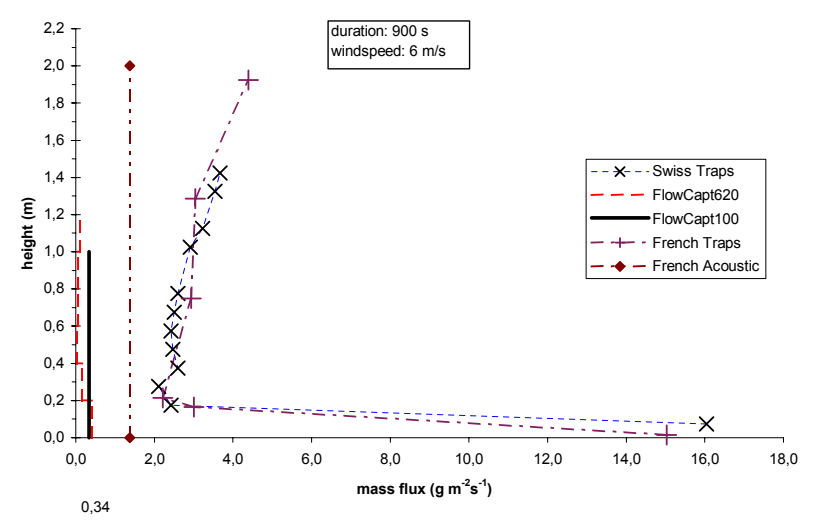

(b)



(d)

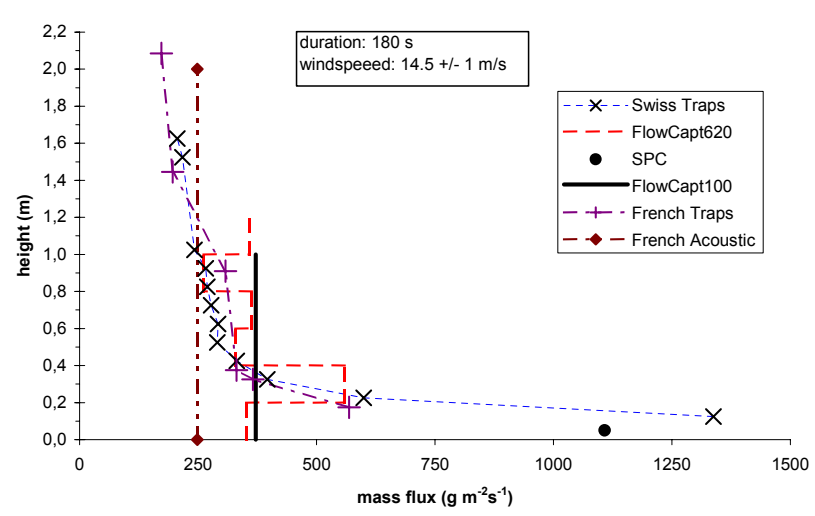

Fig. 2. Comparison of measured mass fluxes for different sensors and experiments. (a) Experiment with a high mass flux rate. (b) Experiment with a low mass flux rate. (c) Experiment with a very low mass flux rate. (d) Experiment with a very high mass flux rate.

crophone at the bottom. The microphone signal is filtered to suppress the low frequency influence of the wind and the influence of very high frequencies. No calibration or further processing is done and the raw sensor signal in $\mathrm{mV}$ is obtained.

In addition to these new sensors, mechanical snow traps are used as reference. To limit flow distortion, small and lightweight traps are used (French Traps). To have exactly the same integration height as for the acoustic sensors, a second type of mechanical trap has been constructed (Swiss Traps or Snow Bags), which measures the complete snow drift profile.

Also part of the experiments is the Japanese Niigata Denki snow particle counter (SPC). This sensor has been used extensively and is known to give an accurate representation of the mass flux at one height (Sato and Kimura, 1993). It is an optical sensor, which determines the size distribution and the mass flux of passing particles. It is unable, however, to determine the direction of the mass flux and is, therefore, not useful when snowfall and snowdrift are occurring simultaneously. The SPC is used as a second reference and thus as a cross-check for the mechanical traps. For some experiments, it also provides an accurate point flux value from the saltation layer close to the ground.
In addition to the drift sensors, several types of wind sensors, such as Young flyers, cup anemometers and one Kaijo Denkij sonic anemometer, have been used. Also, Mellor gauges have been deployed. However, due to their small inlet, they did not collect enough mass to determine a reliable flux value and are, therefore, excluded from the analysis.

\section{Description of experiments}

\subsection{Wind tunnel measurements in Nantes}

In September 1999, a joint experimental campaign was conducted at the climatic wind tunnel of CSTB (Centre Scientifique et Technique des Bâtiments) in Nantes, France. The measurement section of the wind tunnel is $27 \mathrm{~m}$ long, $10 \mathrm{~m}$ wide and $8 \mathrm{~m}$ high (Gandemer, 1992). Snow is artificially produced by three snow cannons. This artificial snow is not dendritic, but consists of little ice pellets with grain diameters between 0.1 and $0.5 \mathrm{~mm}$. Despite the low temperatures used (between -10 and $-20^{\circ} \mathrm{C}$ ), the snow sinters very fast on the ground due to the high humidity.

Figure 1 shows the last part of the probe section of the wind tunnel in Nantes with the measurement devices. From left to right, the positions of the Young wind sensors (1), 


\section{All Valid Experiments CSTB}

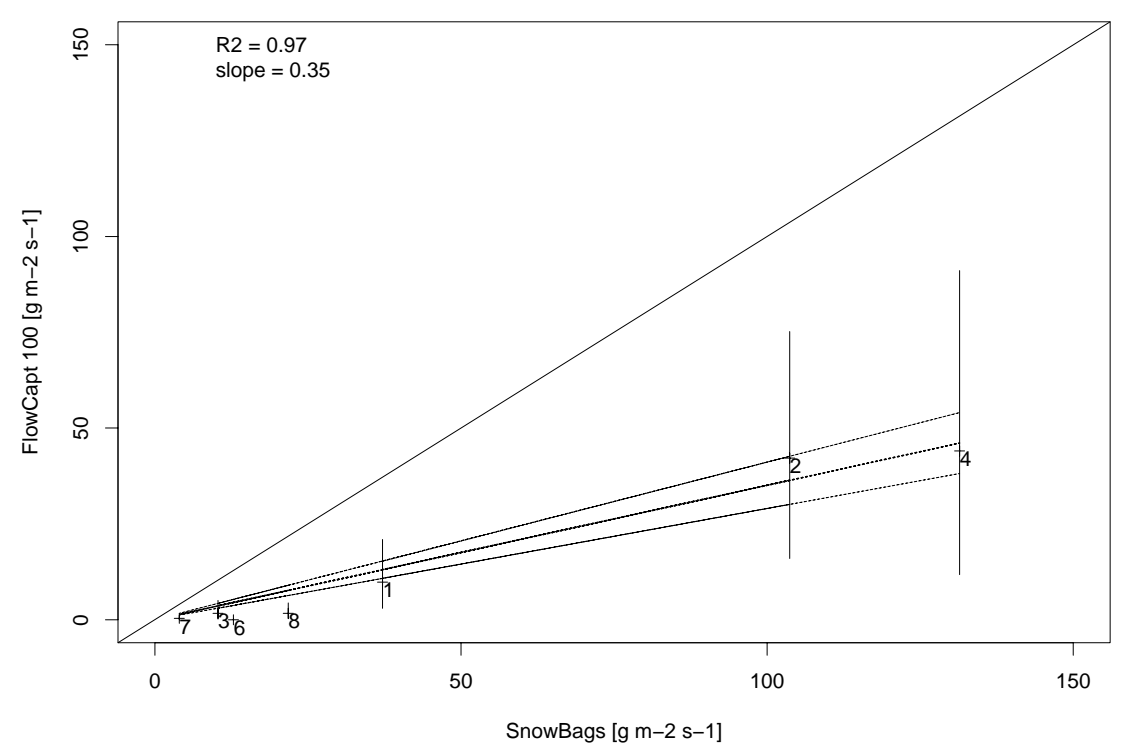

All Experiments Versuchsfeld

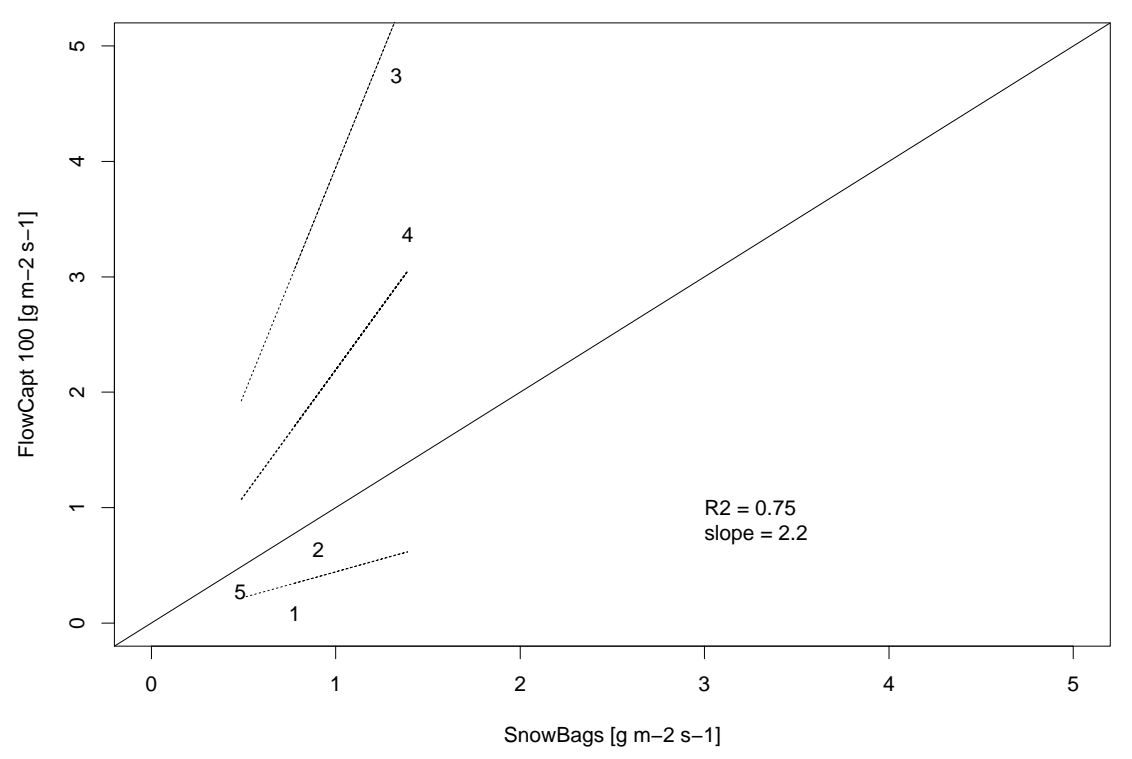

Fig. 3. Linear regression between FlowCapt100 and the Swiss Traps for all valid experiments in the wind tunnel. FlowCapt underestimates the flux consistently. The coefficient of determination is high for the snow in the wind tunnel, which shows little variation. Also shown is a $95 \%$ confidence interval for the slope of the regression.
Fig. 4. Linear regression between FlowCapt100 and the Swiss Traps for the experiments on the Versuchsfeld Weissfluhjoch. The coefficient of determination is much lower than in the wind tunnel due to varying snow conditions. Also shown is a $95 \%$ confidence interval for the slope of the regression. the SPC (2), the ultra-sonic anemometer (3), the Mellor gauges (4), the Swiss Traps or snow bags (5), the six-segment FlowCapt (7) and the one-segment FlowCapt (6), the French acoustic sensor (8) and the French Butterfly Traps (9) are visible. The results will focus on this location, where a complete set of sensors was installed. When discussing the results from the wind tunnel study, the following points have to be taken into account:

- The wind tunnel is not designed to create a turbulent (equilibrium shear friction) boundary layer similar to the atmospheric boundary layer. Thus, the similarity boundary layer relations, such as a logarithmic wind profile, will not apply. This is, however, not a restric- tion for sensor evaluation tests.

- Since the artificial snow is much less variable than natural snow, one possible source of error in the sensor mass flux calibration is not present in the wind tunnel.

- Due to the fast sintering of the artificial snow, the conditions changed during the course of the measurements towards fewer and smaller particles being transported at the same wind speeds.

- Most experiments were conducted with wind speeds below $12 \mathrm{~m} / \mathrm{s}$ that did not cause any acoustical disturbance for the sensors. This was determined by experiments without snow, and both acoustic sensors only showed an 


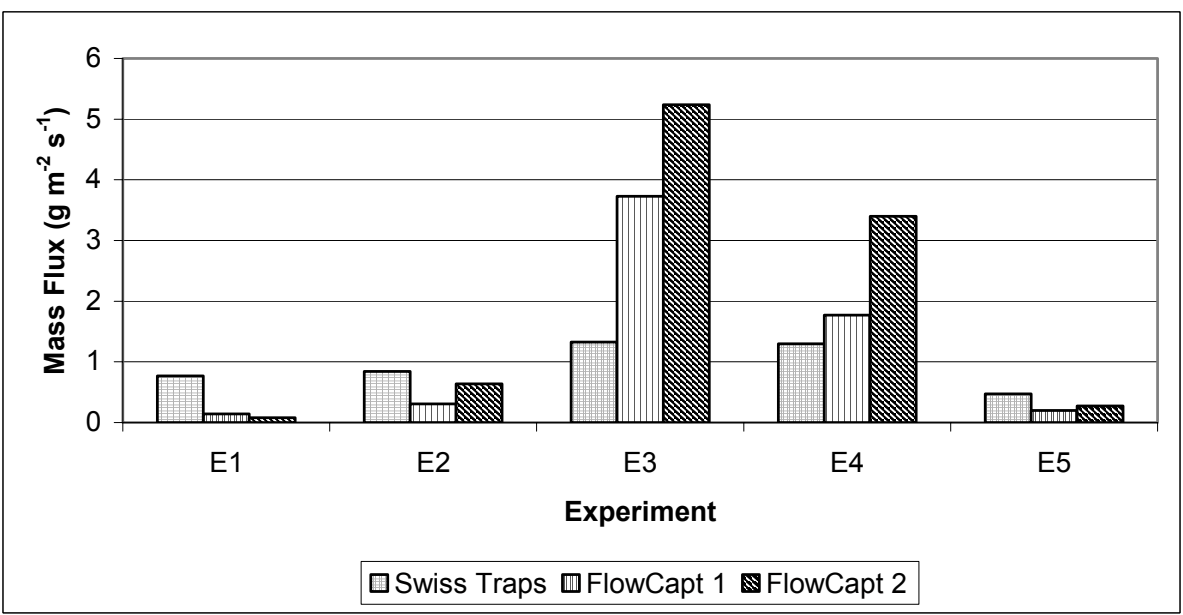

Fig. 5. Flux values for the Weissfluhjoch experimental site measured by the mechanical traps and the two FlowCapt sensors. increasing influence of the wind tunnel noise for wind speed higher than $12 \mathrm{~m} / \mathrm{s}$.

- One particular problem of the wind tunnel was that snow particles did become recirculated through the turbine. This created a second maximum of snow particle concentration at some height above the ground, in addition to the maximum particle concentration in the saltation layer close to the ground. Again, this is not a restriction for our sensor evaluation task.

In addition, some problems with data acquisition and sensor operation occurred. From the wind tunnel, eight valid experiments remained, which are discussed below.

\subsection{Field measurements at Weissfluhjoch Davos}

At our long-term observation and experimental site, "Versuchsfeld Weissfluhjoch Davos", we conducted experiments during the winter 1999/2000. The arrangement of the sensors has been similar to the arrangement in the wind tunnel in Nantes. However, only one type of acoustic sensor (FlowCapt) took part in these field experiments. Following the experience from the wind tunnel measurements, the acoustic sensors had been re-calibrated by the manufacturer. The experiments differ from the wind tunnel experiments. Typically, they lasted for a whole night and, therefore, the reliability of the mechanical traps as a reference is reduced due to slightly variable wind directions. Due to untypical weather situations during that winter, all experiments have been conducted at comparatively high ambient temperatures $\left(>-7^{\circ} \mathrm{C}\right.$ ). Therefore, the snowflakes were rather big and heavy, and differed remarkably from the artificial snow in the wind tunnel. Fortunately, a range of drift intensities could be observed during the five experiments conducted and discussed below. The purpose of the field test was twofold: first, the sensor operation had to be tested in harsh environmental snow drift conditions. Second, the accuracy of the (recalibrated) FlowCapt sensor to measure natural snow drift had to be assessed.

\section{Results}

4.1 Qualitative sensor comparison for representative experiments

In this section, the comparison of the sensor mass flux measurements is presented for four representative experiments. The experiments have been chosen because they are typical for their drift magnitude and cover the range of conditions for the wind tunnel experiments. The results are summarized in Figs. 2 a-d. The mass flux profiles as obtained from the mechanical snow bags (French and Swiss Traps), the mass flux profile from the six-segments FlowCapt, the mean mass fluxes from the one-segment FlowCapt and the French acoustic sensor, and the point mass flux measurement from the SPC are shown. For the French acoustic sensor, which is not calibrated by the manufacturer, a linear calibration (Michaux et al., 2000) has been used: by using all CSTB wind tunnel experiments and the French acoustic sensors, a linear regression calibration has been made from the French Trap mass flux results. This means that an optimal linear calibration for the CSTB experiments is used for the sensor comparisons.

The first experiment (J3E4, Fig. 2a) is a short duration experiment $(460 \mathrm{~s})$ with a high mean wind speed of $10.5 \mathrm{~m} / \mathrm{s}$. The two types of mechanical traps show a very good agreement. Recall that for the mechanical traps the mean height is given and that the French Traps have an inlet depth of $2 \mathrm{~cm}$, as opposed to the inlet depth of $10 \mathrm{~cm}$ for the Swiss Traps. This explains the deviation observed for the lowest two traps. The SPC was set close to the ground and its measurement agrees with the two types of mechanical traps. The two FlowCapts underestimate the flux. From the six-segment FlowCapt flux profile, it also becomes clear that the calibration of the individual segments is inconsistent: the lowest segment gives a much lower flux rate than the second segment, and the whole profile is not similar to the profiles of the mechanical traps. The French acoustic sensor, with its fitted calibration, also underestimates the total flux for this experiment. 
Comparison of Swiss Traps and the SLF Drift Model J3E4 (15.09.99)

CSTB Nantes

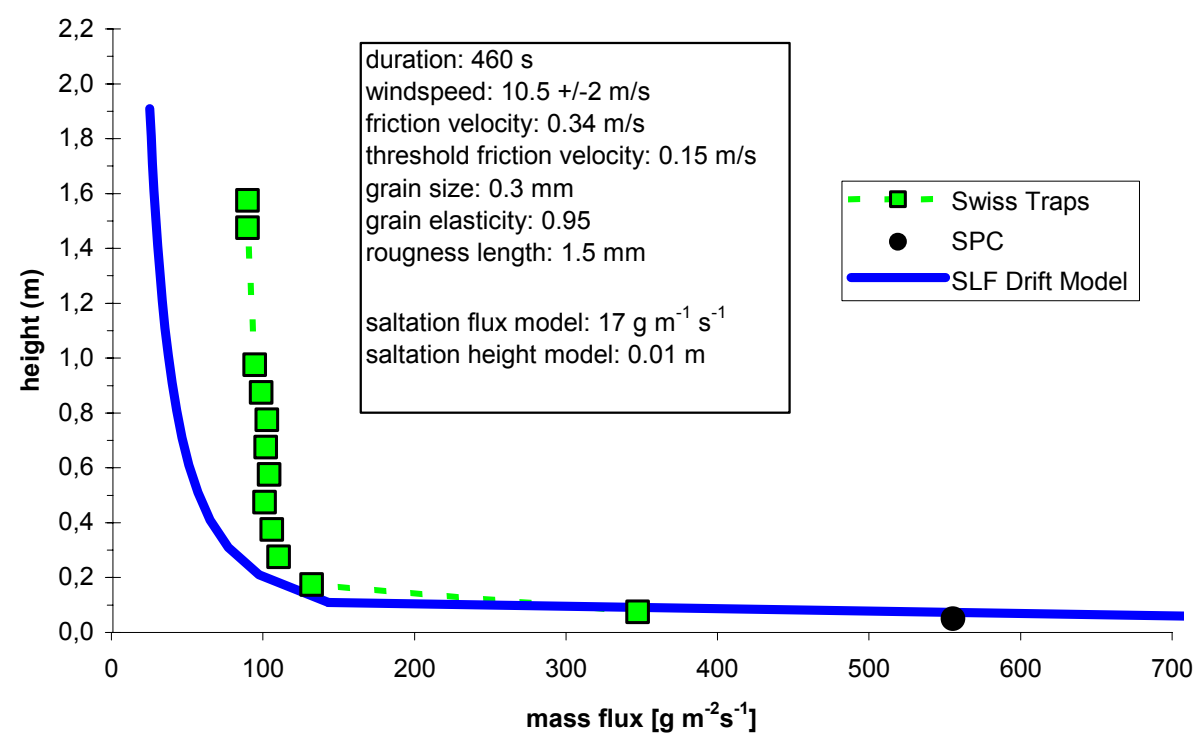

Fig. 6. The new physical SLF snow drift model reproduces the measured fluxes in saltation. Due to the special wind tunnel conditions (recirculating snow, no equilibrium shear friction layer), the suspension fluxes are higher than the equilibrium model predicts.
The second experiment discussed (J3E3, Fig. 2b) had a long duration $(1500 \mathrm{~s})$ and a low wind speed $(6.5 \mathrm{~m} / \mathrm{s})$. The observed mass fluxes are one order of magnitude lower than for J3E4. No explanation can be given for the fact that the Swiss Traps give somewhat lower mass fluxes than the French traps in this case. Consistently, the FlowCapts underestimate again the mass fluxes, but the French acoustic sensor is very close to the mechanically measured fluxes.

In experiment three (J4E4, Fig. 2c), the mass fluxes are again lower by a factor of three. This is due to the low wind speed of $6 \mathrm{~m} / \mathrm{s}$ and the shorter duration. The problem of recirculating snow is clearly visible in the profiles of both types of mechanical traps, which show again a very good agreement. The acoustic sensors underestimate the flux. The mass flux values appear to be too low to be adequately captured by the acoustic sensors.

Experiment four (J3E5, Fig. 2d) has the highest mean wind speed $(14.5 \mathrm{~m} / \mathrm{s})$ of the four experiments. It shows a maximum with flux values of up to $1340 \mathrm{~g} \mathrm{~m}^{-2} \mathrm{~s}^{-1}$ close to the ground. Again, the two types of mechanical traps agree closely. In that experiment, the underestimation through the FlowCapt sensors is much less severe than for the other experiments. This must be the result of noise disturbance. As pointed out above, for wind speeds exceeding $12 \mathrm{~m} / \mathrm{s}$, the wind tunnel noise creates a signal, which increases the measured fluxes.

In summary, valid experiments for the sensor comparison appear to be those for wind speeds higher than $6.5 \mathrm{~m} / \mathrm{s}$ and lower than $12 \mathrm{~m} / \mathrm{s}$. The representative cases discussed show that the FlowCapt acoustic sensors consistently underestimate the fluxes measured by the mechanical traps. The FlowCapt calibration is inconsistent in the sense that the sixsegment sensor is not able to reproduce qualitatively the true flux profile. Even with an idealized (linear) calibration for all
French acoustic sensors, the one sensor used in those representative cases shows predominantly an underestimation of the mechanically measured fluxes.

\subsection{Sensor consistency and snow type influence}

Excluding the experiments with very low mass fluxes on the one hand, and wind speeds above the noise disturbance threshold of $12 \mathrm{~m} / \mathrm{s}$ on the other hand, eight experiments remain. These experiments have been used to test the consistency of the acoustic sensor measurements. For the FlowCapt100 sensor, the result of a linear regression between the Swiss Traps and its flux measurements is given in Fig. 3. The data points as numbers, the range of the FlowCapt flux values for the duration of the experiment, as vertical lines, and a 95\% confidence interval for the regression are shown. A high coefficient of determination $\left(\mathrm{R}^{2}\right)$ of 0.97 results. The sensor consistently gives approximately $35 \%$ of the mechanically measured fluxes (slope of the regression line). An identical result is obtained for the six-segment FlowCapt (not shown). Michaux et al. (2000) have shown that for the French acoustic sensor, a similar consistent picture arises for the CSTB experiments (their Fig. 4). They obtained a coefficient of determination $\left(\mathrm{R}^{2}\right)$ of 0.88 .

Different snow conditions will influence the mass flux measurements of the acoustic sensors. This was tested at the SLF experimental site "Versuchsfeld Weissflujoch". Five experiments have been conducted, each about $20 \mathrm{~h}$ long. This is a major difference to the short duration experiments in the wind tunnel. The results of the linear regression done for the Swiss Traps against FlowCapt is shown in Fig. 4. The individual data points are drawn as numbers and again, a $95 \%$ confidence interval is drawn together with the regression line. The coefficient of determination $\left(\mathrm{R}^{2}\right)$ has dropped to 0.75 . 
Cross Section Comparison

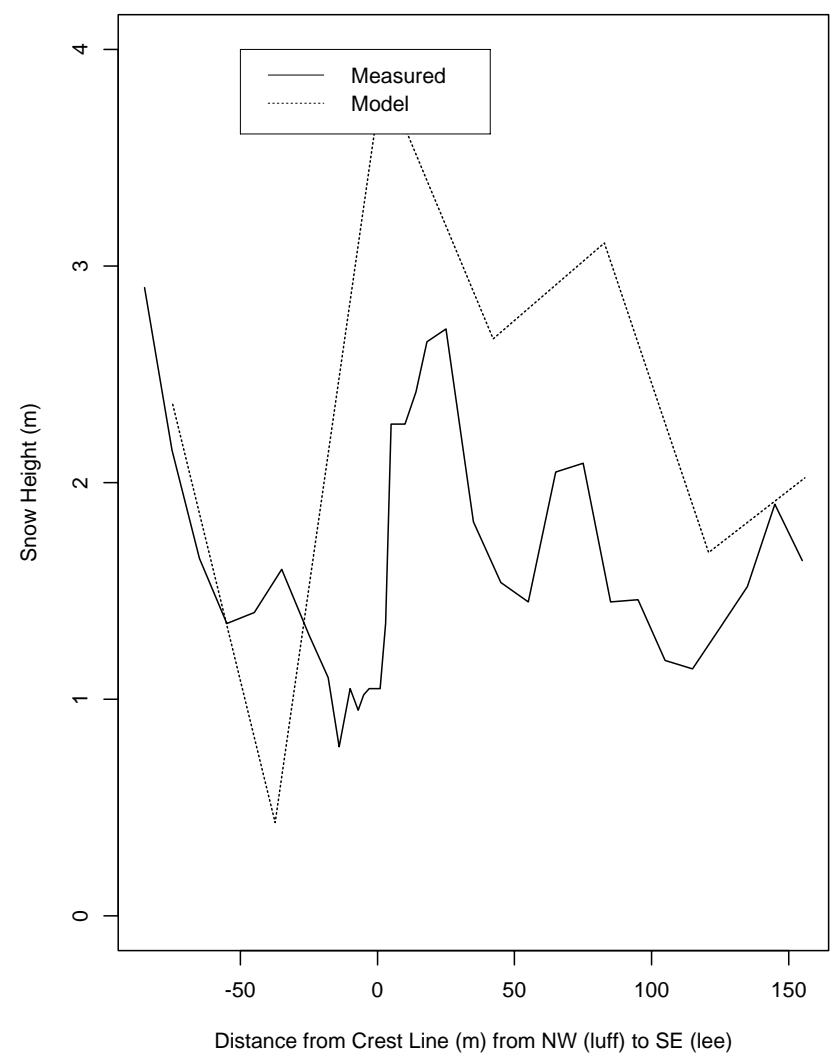

Fig. 7. Comparison of simulated and measured snow distribution along a transect across the Gaudergrat ridge. The measurements have been done manually. The simulation is from a threedimensional snow drift model. Despite the limited model resolution of only $25 \mathrm{~m}$, the deposition pattern in the lee slope is well captured. Figure reproduced from Lehning et al. (2000b).

There are two possible reasons: a) varying wind directions during the long duration experiments invalidate the mechanical trap reference; b) varying snow conditions between the experiments caused the high scatter of the acoustic flux measurements. Since the wind directions and their standard deviations were comparable for all five experiments, point a) is assumed to be insignificant. Figure 5 and Table 1 support hypothesis b): large overestimations of the flux result at high snow densities and temperatures close to the melting point. At cold temperatures and low snow densities, the fluxes are underestimated.

\section{Discussion and comparison with snow drift models}

Our analysis has shown that at present no snow drift sensor exists that could measure accurately and reliably the mass flux for a longer period of time under harsh (snow drift) conditions in remote locations. Even if such as a sensor existed, the data would suffer from the fact that they are point measurements, which are difficult to interpret in terms of snow transported, i.e. onto an avalanche slope. At the same time, snow drift models are improving rapidly. A first suggestion has been made by Lehning et al. (2000a) for a snow drift index based on wind measurements on a crest and snow data from a snow cover model, which is representative for a larger area. Doorschot et al. (2001) have successfully calculated mass fluxes and deposition masses over an alpine ridge. The saltation part of the model has recently been improved and now contains a physical description, which is also valid for steep slopes (Doorschot et al., 2002). Figure 6 is a plot of the new model flux rates compared to the Swiss Traps and the SPC. The flow parameters of friction velocity and roughness length have been estimated from the 3D sonic anemometer data and the wind profile measurements. The snow parameters have been determined experimentally in the tunnel (threshold friction velocity, grain size), or estimated (grain elasticity). A good agreement is found for the saltation flux. The suspension part is based on the assumption of equilibrium vertical diffusion, which is not valid in the wind tunnel (recirculating snow). Since this assumption is also not valid in complex terrain, a realistic description of snow drift must be three-dimensional. For research applications, such models are now available. Figure 7 is a reproduction from Lehning et al. (2000b). It shows that a realistic model description of snow erosion and deposition in very steep terrain is possible. With increasing computer power, operational applications of such models will be possible in the future. These arguments serve to show that models have the potential to replace difficult measurements such as snow drift fluxes in operational applications.

\section{Conclusion}

We confirm the preliminary findings of Font et al. (1998), Michaux et al. (2000) and Jaedicke (2001) that the acoustic sensors are suitable instruments to give qualitative or semi-quantitative information on snow drift events at a specific site. No technical problems have been encountered during our experiments with acoustic snow drift sensors. The sensors can operate reliably for a long duration in harsh conditions. Quantitative calibrations are either not yet available (French acoustic sensor) or not yet good enough (FlowCapt $^{\mathrm{TM}}$ ) to allow for reliable quantitative measurements of drifting snow flux either for research or avalanche warning applications. The problem of an accurate calibration is assumed to be related to the highly variable snow properties and is thus inherent to the measurement principle. A further problem of any drift measuring device is that only drift at one very particular site is measured and thus interpretation in terms of additional loading of avalanche slopes or, for example, total mass lost from a glacier is difficult to obtain. At the same time, operational snow drift models are increasingly able to predict snow drift in complex terrain. Therefore, we except that acoustic sensors will be useful at specific monitoring or index sites. Their main purpose will be to provide plausibility tests and an approximate evaluation for drift model results at sites where a long term experience permits the interpretation of point measurements of drift fluxes. For 
Table 1. Fluxes measured by the mechanical traps and the two FlowCapt acoustic sensors together with the snow characteristics at the Weissfluhjoch Versuchsfeld

\begin{tabular}{cccccc}
\hline & $\begin{array}{c}\text { Swiss Traps } \\
\left(\mathrm{g} \mathrm{m}^{-2} \mathrm{~s}^{-1}\right)\end{array}$ & $\begin{array}{c}\text { FlowCapt 1 } \\
\left(\mathrm{g} \mathrm{m}^{-2} \mathrm{~s}^{-1}\right)\end{array}$ & $\begin{array}{c}\text { FlowCapt 2 } \\
\left(\mathrm{g} \mathrm{m}^{-2} \mathrm{~s}^{-1}\right)\end{array}$ & $\begin{array}{c}\rho \\
\left(\mathrm{kg} \mathrm{m}^{-3}\right)\end{array}$ & $\begin{array}{c}\text { T } \\
\left({ }^{\circ} \mathrm{C}\right)\end{array}$ \\
\hline E1 & 0.769 & 0.143 & 0.080 & 83.00 & -11 \\
E2 & 0.844 & 0.306 & 0.635 & 106.00 & -5 \\
E3 & 1.324 & 3.730 & 5.235 & 318.00 & 0 \\
E4 & 1.300 & 1.768 & 3.399 & 318.00 & 0 \\
E5 & 0.475 & 0.199 & 0.272 & 85.00 & -10 \\
\hline
\end{tabular}

most operational applications, however, snow drift models will be more suitable than drift sensors.

Acknowledgements. Many individuals contributed to the experiments and the discussions. We especially thank C. Sigrist, F. Perret, S. Frutiger, F. Ousset, P. Pugliese, S. Haraldsdottir and acknowledge the great collaboration with the CSTB staff (P. Delpech, O. Viau, M. Dufresne de Virel). Funding was provided by the EU and the Swiss National Science Foundation.

\section{References}

Brown, T. and Pomeroy, J. W.: A blowing snow detector, Cold Reg. Sci. Technol., 16, 167-174, 1989.

Budd, W. F., Dingle, W. B. J., and Radok, U.: The Byrd snow drift project: outline and basic results. In Ruben, M.J. (Ed.), Studies in Antarctic Meteorology. Antarctic Research Series, 9, AGU, Washington, DC, 71-87, 1966.

Chritin, V., Bolognesi, R., and Gubler, H.: FlowCapt: a new acoustic sensor to measure snow drift and wind velocity for avalanche forecasting, Cold Reg. Sci. Technol., 30, 125-133, 1999.

Doorschot, J., Raderschall, N., and Lehning, M.: Measurements and one-dimensional model calculations of snow transport over a mountain ridge, Ann. Glac., 32, 153-158, 2001.

Doorschot, J. and Lehning, M.: Equilibrium saltation: mass fluxes, aerodynamic entrainment and dependence on grain properties,
Bound. Layer Meteorol., in press, 2002.

Jaedicke, C.: Acoustic snowdrift measurements: experiences from the FlowCapt instrument, Cold Reg. Sci. Technol., 32, 71-81, 2001.

Font, D., Naaim-Bouvet, F., and Roussel, M.: Drifting-snow acoustic detector: experimental test in La Molina, Spanish Pyrenees, Ann. Glac., 26, 221-224, 1998.

Gandemer, J.: La soufflerie climatique "Jules Verne", J. Wind Indust. Aerodyn., 43-54, 1992.

Lehning, M., Doorschot, J., and Bartelt, P.: A Snow Drift Index Based on SNOWPACK Model Calculations, Ann. Glac., 31, 382-386, 2000a.

Lehning, M., Doorschot, J., Raderschall, N., and Bartelt, P.: Combining snow drift and SNOWPACK models to estimate snow loading in avalanche slopes, in Snow Engineering, HjorthHansen, Holand, Loset and Norem (eds), Balkema, 113-122, 2000b.

Mellor, M.: Gauging Antarctic drift snow. Antarctic Meteorology. Pergamon, Oxford, 347-354, 1960.

Michaux, J.-L., Naaim-Bouvet, F., and Naaim, M.: The acoustic snowdrift sensor : interests, calibration and results. Proceedings of International Snow Science Workshop, Big Sky, Montana, 390-395, 2000.

Sato, T. and Kimura, T.: Field test of a new snow-particle counter (SPC) system, Ann. Glac., 18, 149-154, 1993.

Schmidt, R. A.: A system that measures blowing snow, USFS research paper RM-194, USDA, Fort Collins, 80, 1977. 